\title{
Theoretical investigation of the doubly stratified flow of an Eyring-Powell nanomaterial via heat generation/absorption
}

\author{
M. Ijaz Khan ${ }^{1, a}$, M. Waqas ${ }^{1}$, A. Alsaedi ${ }^{2}$, T. Hayat ${ }^{1,2}$, and M. Imran Khan ${ }^{3, b}$ \\ 1 Department of Mathematics, Quaid-I-Azam University 45320 Islamabad 44000, Pakistan \\ 2 Nonlinear Analysis and Applied Mathematics (NAAM) Research Group, Department of Mathematics, Faculty of Science, \\ King Abdulaziz University, P. O. Box 80257, Jeddah 21589, Saudi Arabia \\ ${ }^{3}$ Heriot Watt University, Edinburgh Campus, Edinburgh EH14 4AS, UK
}

Received: 2 October 2017 / Revised: 10 October 2017

Published online: 27 November 2017

(C) The Author(s) 2017. This article is published with open access at Springerlink.com

\begin{abstract}
The mixed convective flow of an Eyring-Powell nanomaterial in a doubly stratified medium is addressed in this paper. The stretching surface has varying thickness. The nanofluid model given by Buongiorno is utilized in the formulation of energy and concentration expressions. Heat generation is also retained. Ordinary differential systems are obtained by utilizing the transformations procedure. Homotopy series solutions containing exponentially functions are developed. Significant characteristics of influential variables for velocity, temperature, nanoparticle concentration, skin friction coefficient and Nusselt and Sherwood numbers are reported through graphs and tables. It is found that stratification phenomenon leads to a decay in temperature and nanoparticle concentration.
\end{abstract}

\section{Nomenclature}

\begin{tabular}{|ll|ll|}
\hline$u, v$ & Velocity components & $\alpha$ & Wall thickness parameter \\
\hline$x, y$ & Space coordinates & $\epsilon, \delta$ & Material parameters \\
\hline$\rho_{f}$ & Density of base fluid & $\lambda$ & Thermal buoyany parameter \\
\hline$T$ & Temperature & $N$ & Ratio of thermal to concentration buoyany forces \\
\hline$T_{\infty}$ & Ambient temperature & $\operatorname{Pr}$ & Prandtl number \\
\hline$C$ & Concentration & $S_{1}$ & Thermal stratification parameter \\
\hline$C_{\infty}$ & Ambient concentration & $S_{2}$ & Solutal stratification parameter \\
\hline$g$ & Gravitational acceleration & $S c$ & Schmidt number \\
\hline$B_{T}$ & Thermal expansion coefficient & $N_{b}$ & Brownian motion parameter \\
\hline$B_{C}$ & Solutal expansion coefficient & $N_{t}$ & Thermophoresis parameter \\
\hline$\alpha^{*}=\frac{k}{(\rho c)_{f}}$ & Thermal diffusivity & $S$ & Heat generation/absorption parameter \\
\hline$k$ & Thermal conductivity & $A_{1}$ & Small parameter regarding surface \\
\hline$(\rho c)_{f}$ & Specific heat of fluid & & is adquately thin \\
\hline$(\rho c)_{p}$ & Specific heat of nanoparticles & $b, a, a_{1}$ & Dimensional \\
\hline$Q(x)$ & Non-uniform heat generation/absorption & $a_{2}, d_{1}, d_{2}$ & Constants \\
\hline$\tau$ & Heat/capacity ratio & $T_{0}, C_{0}$ & Reference temperature and concentration \\
\hline$D_{B}$ & Brownian diffusion coefficient & $n$ & Power law index \\
\hline$D_{T}$ & Thermophoresis diffusion coefficient & $\tau$ & Heat capacity ratio \\
\hline$Q_{0}$ & Heat generation/absorption coefficient & $N u_{x}$ & Local Nusselt number \\
\hline$G r_{x}$ & Grashof number due to temperature & $S h_{x}$ & Local Sherwood number \\
\hline$G r_{x}^{*}$ & Grashof number due to concentration & $\mathrm{Re}$ & Reynolds number \\
\hline$q_{w}$ & Wall heat flux & $\Psi$ & Stream function \\
\hline$q_{m}$ & Wall mass flux & $\xi$ & Dimensionless similarity variable \\
\hline
\end{tabular}

\footnotetext{
a e-mail: mikhan@math.qau.edu.pk

b e-mail: mk42@hw.ac.uk (corresponding author)
} 


\section{Introduction}

Cooling of electronic devices is one of the main challenges of new-generation technology. The existing conventional heat transport liquids are incapable to produce appropriate cooling in the systems of industries. Such situation led to the evolution of the latest technology, called nanotechnology, which is found through colloids of ultrafine nanoparticles $(\leq 100 \mathrm{~nm})$ in ethylene glycol, oil or water. Such colloids are designated as nanoliquids. The nanoparticles included in the nanoliquid are normally made of nitrides, carbides, oxides, metals, graphites and carbon nanotubes. There are certain physical and chemical features of colloids of nanoparticles that make them extremely trustworthy in the manufacturing of numerous industrial and engineering products, comprising ceramics, drugs delivery systems, coatings, foods, paints, etc. Such liquids having effective utilizations in processes like cooling of engines/electronic devices, heat exchanger, manufacturing, transportations, etc., improving the thermal performance of the nanomaterial, among which induced micro-convection, Brownian motion of nanoparticles, particle-to-particle connection through inter-particle potential, thermal diffusion, thermophoresis, etc. [1,2]. Choi [3] reported the experimental analysis on nanoparticles and observed that the presence of nanoparticles in the base liquid remarkably enhances the thermal conductivity of the working liquid. Buongiorno [4] discovered that thermophoretic and Brownian motion are important factors. The analysis reported in [4] is extended by numerous researchers considering distinct physical aspects (see refs. [5-10]).

Double stratification and mixed convection in fluid flow problems have attracted exceptional attention of researchers owing to their ample utilizations. Such problems usually appeared in engineering and industrial applications as, e.g., heat rejection into the environment, like rivers, seas and lakes; thermal energy storage systems, like solar ponds and heat transport from thermal source, like the condensers of power plants [11]. Mixed convective stratified flow of a magneto-micropolar and of a thixotropic nanofluid in the presence of the heat generation effect are studied by Mishra et al. [12] and Hayat et al. [13]. Abbasi et al. [14] explored the thermally radiating stratified Jeffrey fluid flow with Brownian moment and thermophoresis. Besthapu et al. [15] reported double stratification and viscous dissipation effects in the mixed convective nanoliquid flow induced by an exponentially stretched surface. Characteristics of mixed convection in a doubly stratified Oldroyd-B nanofluid flow with heat generation were studied by Waqas et al. [16]. Moreover, the convection heat problems associated with heat generation within a liquid are of great importance: for instance, there are various demands in energy associated problems. Mention may be made to solidification of costing and chilling of underground electric cables. Few studies in this direction can be consulted through refs. [17-20].

Analyses of nonlinear fluid models induced by a stretching sheet are of extraordinary significance owing to their several applications in engineering: for instance, polymer sheet extrusion, sewer pipes, blood vessels, melt spinning processes, water pipes, plastic sheets aerodynamic extrusion, drying and cooling of paper, irrigation of channels, glass fibre production, etc. Crane [21] theoretically addressed the boundary layer flow towards stretched surfaces. The analysis in [21] was extended by several researchers considering distinct physical features for the illustration of the characteristics of rotation, heat/mass transfer, stagnation point flow, suction/injection, mixed convection, magnetohydrodynamics (MHD), chemical reaction, viscous dissipation, heat generation/absorption, Joule heating, thermal radiation or diverse feasible combinations of the aforesaid effects (see [22-25]). The stretching sheet, in the aforementioned investigations, is considered with constant thickness. The stretching sheet with varying thickness has effective engineering and physical backgrounds. The utilization of a varying thickness is clearly valuable to reduce the mass of structural items and develop the material applications [26]. Few recent analyses dealing with varying thickness can be seen in refs. [27-30].

The above-mentioned studies show that double-stratification characteristics in nanofluid flow with varying thickness are not yet reported. Therefore, our target here is to venture further in this regime by considering the doubly stratified stretching flow of a non-Newtonian (Eyring-Powell) liquid model. Brownian motion, mixed convection, thermophoresis and heat generation are also considered. The homotopic technique [31-45] is chosen for the computations of nonlinear systems. The diverse aspects of influential constraints for velocity, temperature and concentration of nanoparticles are visualized and interpreted via figures.

\section{Formulation}

Here the stretched flow of an Eyring-Powell nanomaterial in the presence of magnetohydrodynamics (MHD) and mixed convection is formulated. The velocity of a stretching sheet $\left(U_{w}(x)=U_{0}(x+b)^{n}\right)$ is considered at $y=A_{1}(x+b)^{\frac{1-n}{2}}$ (coefficient $A_{1}$ is selected to be small to illustrate the flow along the stretching sheet). The linear case of moving sheet is reduced if we take $n=1$. The surface is retained at varying temperature $\left(T=T_{w}=T_{0}+a_{1}(x+b)\right)$ and concentration $\left(C=C_{w}=C_{0}+d_{1}(x+b)\right)$ and (temperature, concentration) away from the surface are $\left(T \rightarrow T_{\infty}=T_{0}+a_{2}(x+b)\right)$ and $\left(C \rightarrow C_{\infty}=C_{0}+d_{2}(x+b)\right.$ ) (see fig. 1). The choice of a small magnetic Reynolds number leads to omission of the induced field. Moreover, the Buongiorno model for nanofluid comprising thermophoresis and Brownian moment is considered for modeling energy and concentration expressions. The effects of the Joule heating are retained. Besides, 


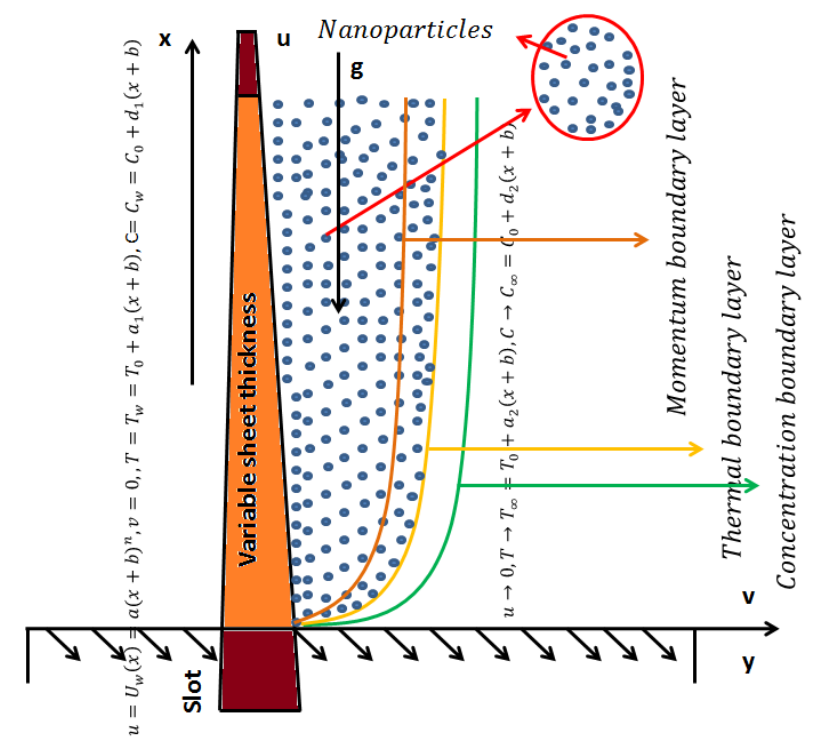

Fig. 1. Geometry of the flow problem.

thermal radiation and viscous dissipation are not taken into account. The relevant boundary layer problem satisfies [35]:

$\frac{\partial u}{\partial x}+\frac{\partial v}{\partial y}=0$

$u \frac{\partial u}{\partial x}+v \frac{\partial u}{\partial y}=\left(\nu+\frac{1}{\rho_{f} \beta c}\right) \frac{\partial^{2} u}{\partial y^{2}}-\frac{1}{2 \rho_{f} \beta c^{3}}\left(\frac{\partial u}{\partial y}\right)^{2} \frac{\partial^{2} u}{\partial y^{2}}+g B_{T}\left(T-T_{\infty}\right)+g B_{C}\left(C-C_{\infty}\right)$,

$u \frac{\partial T}{\partial x}+v \frac{\partial T}{\partial y}=\frac{k}{(\rho c)_{f}} \frac{\partial^{2} T}{\partial y^{2}}+\tau\left[D_{B} \frac{\partial C}{\partial y} \frac{\partial T}{\partial y}+\frac{D_{T}}{T_{\infty}}\left(\frac{\partial T}{\partial y}\right)^{2}\right]+\frac{Q(x)}{(\rho c)_{f}}\left(T-T_{\infty}\right)$,

$u \frac{\partial C}{\partial x}+v \frac{\partial C}{\partial y}=D_{B} \frac{\partial^{2} C}{\partial y^{2}}+\frac{D_{T}}{T_{\infty}} \frac{\partial^{2} T}{\partial y^{2}}$,

$u=U_{w}(x)=a(x+b)^{n}, \quad v=0, \quad T=T_{w}=T_{0}+a_{1}(x+b), \quad C=C_{w}=C_{0}+d_{1}(x+b), \quad$ at $\quad y=A_{1}(x+b)^{\frac{1-n}{2}}$,

$u \rightarrow 0, \quad T \rightarrow T_{\infty}=T_{0}+a_{2}(x+b), \quad C \rightarrow C_{\infty}=C_{0}+d_{2}(x+b), \quad$ when $\quad y \rightarrow \infty$.

Introducing $[35,36]$

$$
\begin{aligned}
\psi & =\sqrt{\frac{2}{n+1} \nu a(x+b)^{n+1}} F(\xi), \quad \xi=\sqrt{\frac{n+1}{2} \frac{a}{\nu}(x+b)^{n-1}} y, \\
u & =a(x+b)^{n} F^{\prime}(\xi), \quad v=-\sqrt{\frac{n+1}{2} \nu a(x+b)^{n-1}}\left(F(\xi)+\xi \frac{n-1}{n+1} F^{\prime}(\xi)\right), \\
\Theta(\xi) & =\frac{T-T_{\infty}}{T_{w}-T_{0}}, \quad \Phi(\xi)=\frac{C-C_{\infty}}{C_{w}-C_{0}},
\end{aligned}
$$

eq. (1) is fulfilled trivially, while eqs. (2)-(5) take the form

$$
\begin{aligned}
& (1+\epsilon) F^{\prime \prime \prime}+F F^{\prime \prime}-\frac{2 n}{n+1} F^{2}-\epsilon \delta\left(\frac{n+1}{2}\right) F^{\prime^{2}} F^{\prime \prime \prime}+\frac{2 \lambda}{n+1}[\Theta+N \Phi]=0 \\
& \Theta^{\prime \prime}+\operatorname{Pr} F \Theta^{\prime}-\left(\frac{2}{n+1}\right) \operatorname{Pr} F^{\prime} \Theta-\left(\frac{2}{n+1}\right) \operatorname{Pr} S_{1} F^{\prime}+\operatorname{Pr} N_{b} \Theta^{\prime} \Phi^{\prime}+\operatorname{Pr} N_{t} \Theta^{\prime 2}+\left(\frac{2}{n+1}\right) \operatorname{Pr} S \Theta=0
\end{aligned}
$$




$$
\begin{aligned}
& \Phi^{\prime \prime}+S c F \Phi^{\prime}-\left(\frac{2}{n+1}\right) S c F^{\prime} \Phi-\left(\frac{2}{n+1}\right) S c S_{2} F^{\prime}+\frac{N_{t}}{N_{b}} \Theta^{\prime \prime}=0, \\
& F(\alpha)=\alpha\left(\frac{1-n}{1+n}\right), \quad F^{\prime}(\alpha)=1, \\
& \Theta(\alpha)=1-S_{1}, \quad \Phi(\alpha)=1-S_{2} \quad \text { at } \alpha=A_{1} \sqrt{\frac{n+1}{2}} \frac{a}{\nu} \\
& F^{\prime}(\alpha) \rightarrow 0, \quad \Theta(\alpha) \rightarrow 0, \quad \Phi(\alpha) \rightarrow 0 \quad \text { as } \alpha \rightarrow \infty .
\end{aligned}
$$

Here prime $\left(^{\prime}\right)$ characterizes the derivative corresponding to $\xi$. Considering $F(\xi)=f(\xi-\alpha)=f(\eta), \Theta(\xi)=\theta(\xi-\alpha)=$ $\theta(\eta)$ and $\Phi(\xi)=\phi(\xi-\alpha)=\phi(\eta)$, we obtain

$$
\begin{aligned}
& (1+\epsilon) f^{\prime \prime \prime}+f f^{\prime \prime}-\frac{2 n}{n+1} f^{\prime 2}-\epsilon \delta\left(\frac{n+1}{2}\right) f^{\prime^{2}} f^{\prime \prime \prime}+\frac{2 \lambda}{n+1}[\theta+N \phi]=0 \\
& \theta^{\prime \prime}+\operatorname{Pr} f \theta^{\prime}-\left(\frac{2}{n+1}\right) \operatorname{Pr} f^{\prime} \theta-\left(\frac{2}{n+1}\right) \operatorname{Pr} S_{1} f^{\prime}+\operatorname{Pr} N_{b} \theta^{\prime} \phi^{\prime}+\operatorname{Pr} N_{t} \theta^{\prime 2}+\left(\frac{2}{n+1}\right) \operatorname{Pr} S \theta=0 \\
& \phi^{\prime \prime}+S c f \phi^{\prime}-\left(\frac{2}{n+1}\right) S c f^{\prime} \phi-\left(\frac{2}{n+1}\right) S c S_{2} f^{\prime}+\frac{N_{t}}{N_{b}} \theta^{\prime \prime}=0 \\
& f(0)=\alpha\left(\frac{1-n}{1+n}\right), \quad f^{\prime}(0)=1 \\
& \theta(0)=1-S_{1}, \quad \phi(0)=1-S_{2}, \\
& f^{\prime}(\infty) \rightarrow 0, \quad \theta(\infty) \rightarrow 0, \quad \phi(\infty) \rightarrow 0 .
\end{aligned}
$$

The involved variables are

$$
\begin{aligned}
\epsilon & =\frac{1}{\mu \beta c}, \quad \delta=\frac{a^{3}(x+b)^{3 n-1}}{2 c^{2} \nu}, \quad \lambda=\frac{G r_{x}}{\operatorname{Re}_{x}^{2}}, \quad N=\frac{G r_{x}^{*}}{\operatorname{Re}_{x}^{2}}, \\
G r_{x} & =\frac{g \beta_{T}\left(T_{w}-T_{0}\right)(x+b)^{3}}{\nu^{2}}, \quad G r_{x}^{*}=\frac{g \beta_{C}\left(C_{w}-C_{0}\right)(x+b)^{3}}{\nu^{2}}, \quad \operatorname{Re}_{x}=\frac{x U_{w}(x)}{\nu}, \\
\operatorname{Pr} & =\frac{\nu}{\alpha^{*}}, \quad \alpha^{*}=\frac{k}{(\rho c)_{f}}, \quad S_{1}=\frac{a_{2}}{a_{1}}, \quad S_{2}=\frac{d_{2}}{d_{1}}, \quad S=\frac{Q_{0}}{(\rho c)_{f} a}, \quad \tau=\frac{(\rho c)_{p}}{(\rho c)_{f}} \\
N_{t} & =\frac{\tau D_{T}\left(T_{w}-T_{0}\right)}{T_{\infty} \nu}, \quad N_{b}=\frac{\tau D_{B}\left(C_{w}-C_{0}\right)}{\nu}, \quad S c=\frac{\nu}{D_{B}} .
\end{aligned}
$$

The local Nusselt $\left(N u_{x}\right)$ and Sherwood $\left(S h_{x}\right)$ numbers are expressed as

with

$$
N u_{x}=\frac{x q_{w}}{k\left(T_{w}-T_{0}\right)}, \quad S h_{x}=\frac{x q_{m}}{D_{B}\left(C_{w}-C_{0}\right)},
$$

$$
q_{w}=-k\left(\frac{\partial T}{\partial y}\right)_{y=A_{1}(x+b)^{\frac{1-n}{2}}}, \quad q_{m}=-D_{B}\left(\frac{\partial C}{\partial y}\right)_{y=A_{1}(x+b)^{\frac{1-n}{2}}} .
$$

The dimensionless expression for eq. (16) is

$$
N u_{x} \operatorname{Re}_{x}^{-\frac{1}{2}}=-\sqrt{\frac{n+1}{2}} \theta^{\prime}(0), \quad S h_{x} / \operatorname{Re}_{x}^{-\frac{1}{2}}=-\sqrt{\frac{n+1}{2}} \phi^{\prime}(0) .
$$

\section{Convergence analysis}

The idea of Liao [31] is adopted to express the solutions. For meaningful outcomes it is, obviously, crucial to authenticate the convergence of the developed series solutions. Such outcomes depend on $\hbar$, through which convergence can be controlled. To achieve the convergence region, we designed the curves in fig. 2 . This figure shows that the convergence regions lie in the ranges $-1.60 \leq \hbar_{f} \leq-0.25,-1.65 \leq \hbar_{\theta} \leq-0.35,-1.50 \leq \hbar_{\phi} \leq-0.35$. Moreover, the convergence is ensured also numerically through table 1. Clearly 15th-order approximations are enough for the convergence of $f^{\prime \prime}(0)$, $\theta^{\prime}(0)$ and $\phi^{\prime}(0)$. Influences of $S_{1}, N_{t}, S, \operatorname{Pr}, N_{b}, S_{2}$ and $S c$ on heat $\left(N u_{x} \operatorname{Re}_{x}^{-\frac{1}{2}}\right)$ and mass $\left(S h_{x} \operatorname{Re}_{x}^{-\frac{1}{2}}\right)$ transfer rates are addressed through tables 2 and 3. Clearly, larger Pr and $N_{b}$ correspond to lower $N u_{x} \operatorname{Re}_{x}^{-\frac{1}{2}}$, whereas a reverse situation is noticed for $S_{1}, N_{t}, S$ (see table 2). Moreover, the mass transfer $\left(S h_{x} \operatorname{Re}_{x}^{-\frac{1}{2}}\right)$ increases for larger $N_{b}$ and $S c$, whereas it decreases with $N_{t}$ and $S_{2}$. 


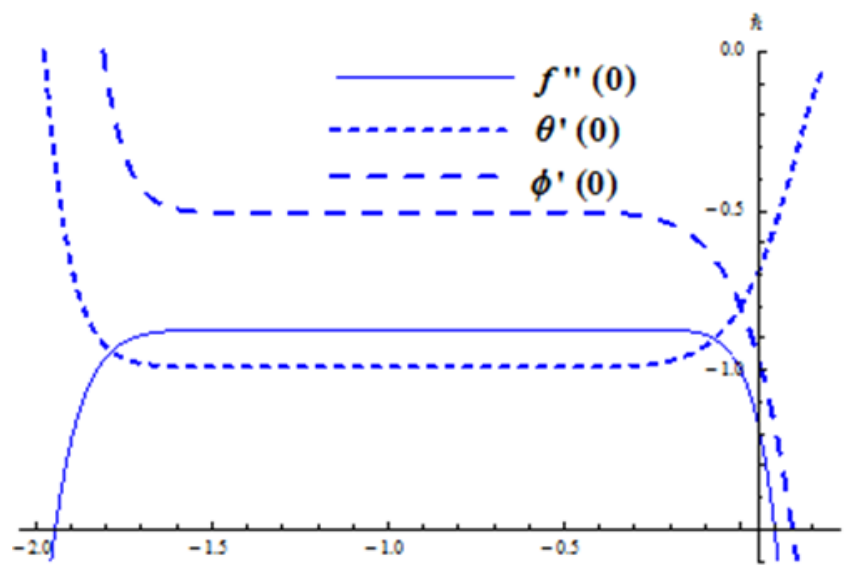

Fig. 2. $\hbar$-curve for $f, \theta$ and $\phi$.

Table 1. Convergent solutions for distinct order approximations when $\lambda=S=N_{t}=N_{b}=0.1, \epsilon=S_{1}=\delta=S_{2}=0.2$, $N=0.3, n=0.9, \operatorname{Pr}=S c=1.2$.

\begin{tabular}{lccc}
\hline Order of approximations & $-f^{\prime \prime}(0)$ & $-\theta^{\prime}(0)$ & $-\phi^{\prime}(0)$ \\
\hline 1 & 0.8789 & 0.8971 & 0.6585 \\
5 & 0.8720 & 0.9893 & 0.5069 \\
10 & 0.8728 & 0.9898 & 0.5047 \\
12 & 0.8727 & 0.9896 & 0.5054 \\
15 & 0.8727 & 0.9896 & 0.5054 \\
20 & 0.8727 & 0.9896 & 0.5054 \\
30 & 0.8727 & 0.9896 & 0.5054 \\
\hline
\end{tabular}

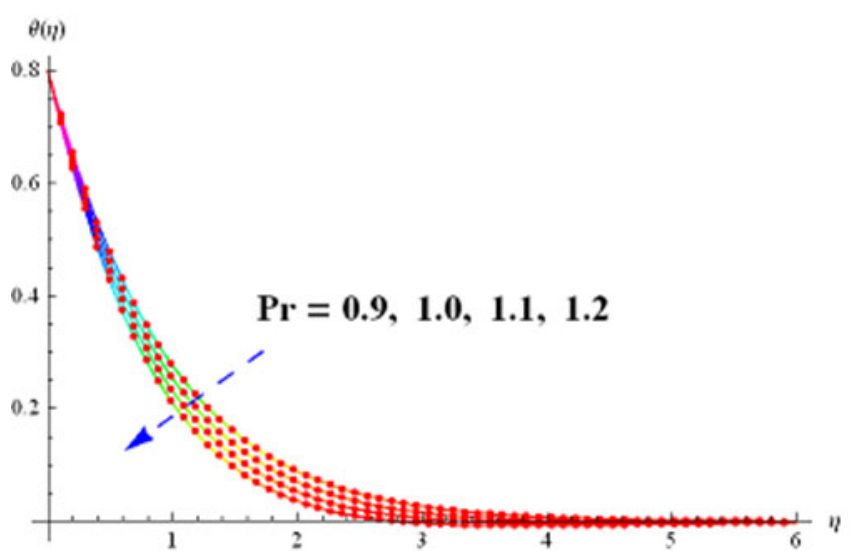

Fig. 3. $\theta$ via $\operatorname{Pr}$.

\section{Analysis}

Outcomes of influential variables on velocity $\left(f^{\prime}\right)$, temperature $(\theta)$, nanoparticles concentration $(\phi)$, skin-friction coefficient $\left(C_{f} \operatorname{Re}_{x}^{1 / 2}\right)$, Nusselt $\left(N u_{x}\right)$ and Sherwood $\left(S h_{x}\right)$ numbers are elaborated in this section. Figures 2-10 along with tables 2 and 3 are arranged for such intention.

The impact of $\operatorname{Pr}$ on $\theta$ is presented in fig. 3. It is found that thermal layer thickness and $\theta$ are decaying functions of Pr. A larger Pr yields weaker thermal diffusion, which corresponds to lower $\theta$. Figure 4 illustrates the effect of $S_{1}$ on $\theta$. Clearly, the thermal layer thickness and $\theta$ are lower for $S_{1}$, since the temperature difference decays between ambient and surface liquid, so $\theta$ reduces. The importance of $S$ on $\theta$ is elaborated in fig. 5 . As expected, $\theta$ increases with $S$. It is due to the fact that more heat is produced when $S$ increases. Therefore, $\theta$ increases. Figures 6 and 7 show the influences of $N_{t}$ and $N_{b}$ on $\theta$. It is noted from fig. 6 that the thickness of the corresponding layer and $\theta$ increase when $N_{b}$ increases. 


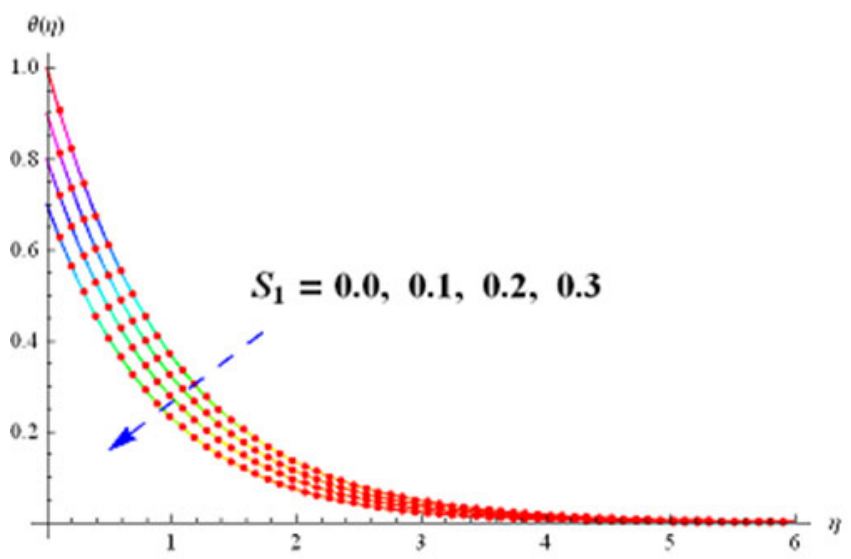

Fig. 4. $\theta$ via $S_{1}$.

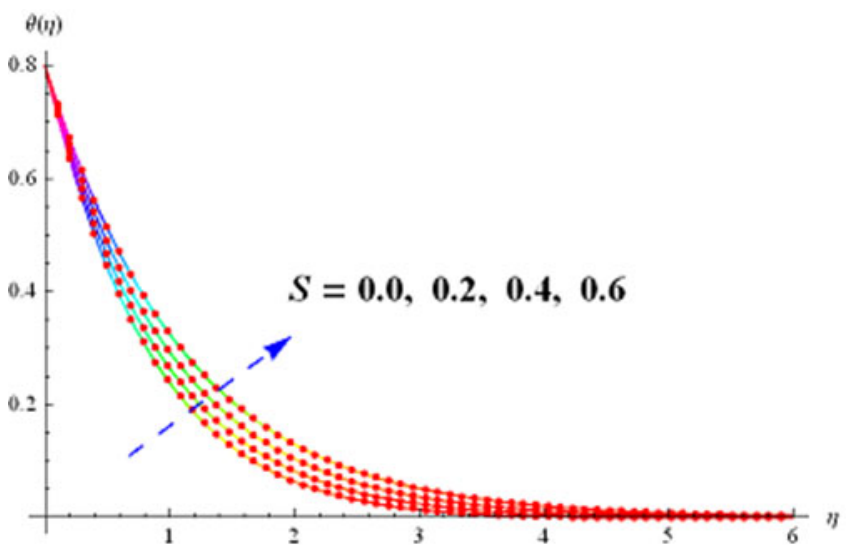

Fig. 5. $\theta$ via $S$.

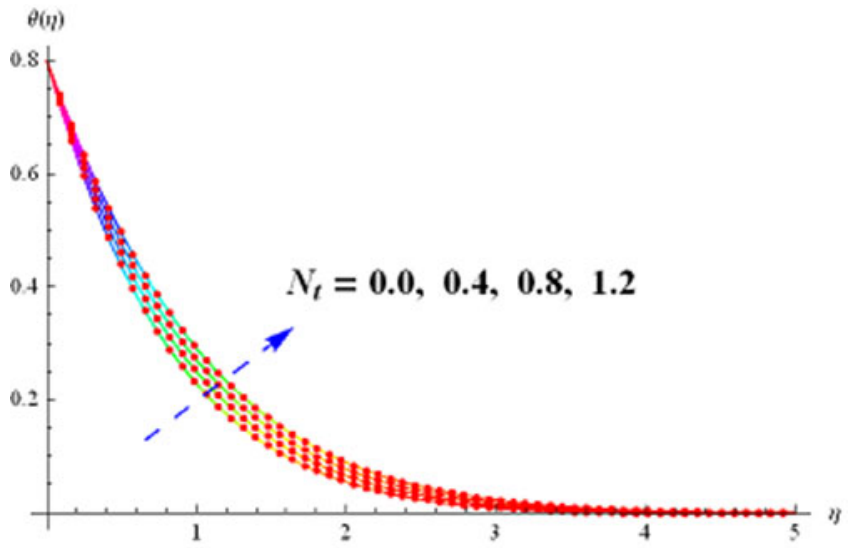

Fig. 6. $\theta$ via $N_{t}$. 
Table 2. Local Nusselt $\left(N u_{x} \operatorname{Re}_{x}^{-\frac{1}{2}}\right)$ number via $S_{1}, N_{t}, S, \operatorname{Pr}$ and $N_{b}$.

\begin{tabular}{llllll}
\hline$S_{1}$ & $N_{t}$ & $S$ & $\operatorname{Pr}$ & $N_{b}$ & $N u_{x} \operatorname{Re}_{x}^{-\frac{1}{2}}$ \\
\hline 0.0 & 0.1 & 0.2 & 0.1 & & 1.0108 \\
0.3 & & & & & 0.9405 \\
0.6 & & & & & 0.8653 \\
0.2 & 0.0 & & & & 0.9863 \\
& 0.3 & & & & 0.9235 \\
& 0.6 & & & & 0.8675 \\
& 0.1 & 0.0 & & & 1.0056 \\
& & 0.2 & & & 0.9214 \\
& & 0.4 & & & 0.8768 \\
& & 0.1 & 0.9 & & 0.8119 \\
& & 1.0 & & 0.8656 \\
& & 1.1 & & 0.9163 \\
& & & 0.2 & 0.9265 \\
& & & 0.4 & 0.8549 \\
& & & 0.7 & 0.7577 \\
\hline
\end{tabular}

Table 3. Local Sherwood $\left(S h_{x} \operatorname{Re}_{x}^{-\frac{1}{2}}\right)$ number via $S_{2}, N_{t}, S c$ and $N_{b}$.

\begin{tabular}{lllll}
\hline$S_{2}$ & $N_{t}$ & $S c$ & $N_{b}$ & $S h_{x} \operatorname{Re}_{x}^{-\frac{1}{2}}$ \\
\hline 0.0 & 0.1 & 0.2 & & 0.5702 \\
0.3 & & & & 0.4537 \\
0.6 & & & & 0.3369 \\
0.2 & 0.0 & & & 1.0683 \\
& 0.07 & & & 0.6613 \\
& 0.15 & & & 0.2171 \\
& 0.1 & 0.9 & & 0.2659 \\
& & 1.0 & & 0.3463 \\
& & 1.1 & & 0.4214 \\
& & 1.2 & 0.2 & 0.7964 \\
& & & 0.4 & 0.9476 \\
& & & 0.7 & 1.0115 \\
\hline
\end{tabular}

In fact more heat is produced by the arbitrary moment of liquid particles for larger $N_{b}$, which results in temperature enhancement. Moreover, fig. 7 shows that $\theta$ is higher for $N_{t}$. In the thermophoresis phenomenon the heated particles are drawn aside from the heated surface to the cold region. This fact leads to temperature enhancement.

Analysis of $S_{2}$ on $\phi$ is addressed in fig. 8. Here $\phi$ shows decaying characteristics for $S_{2}$. Such situation is noted because concentration difference reduces between ambient and surface liquid. Figure 9 shows $\phi$ variation for $N_{t}$. The thermal conductivity of the liquid clearly increases within the frame of nanoparticles. Therefore, larger $N_{t}$ help liquid thermal conductivity increase. Therefore, more concentration is achieved through higher thermal conductivity. Figure 10 shows the variation of $\theta$ for variation in $S c$. Increment in $S c$ reduces $\phi$ and nanoparticle concentration. The Schmidt number represents the ratio of momentum to mass diffusivities. Hence an increment in $S c$ results in a decrement of mass diffusivity, which results in a decrease in $\phi$ and in the concentration layer thickness. Figure 11 shows the influence of $N_{b}$ on $\phi$. Increase in the values of $N_{b}$ yields less concentration $(\phi)$. Physically, the intensified Brownian moment creates a strong moment of nanoparticles, which are then pushed from the moving surface to the quiescent liquid, thereby decreasing the concentration within the boundary layer. 


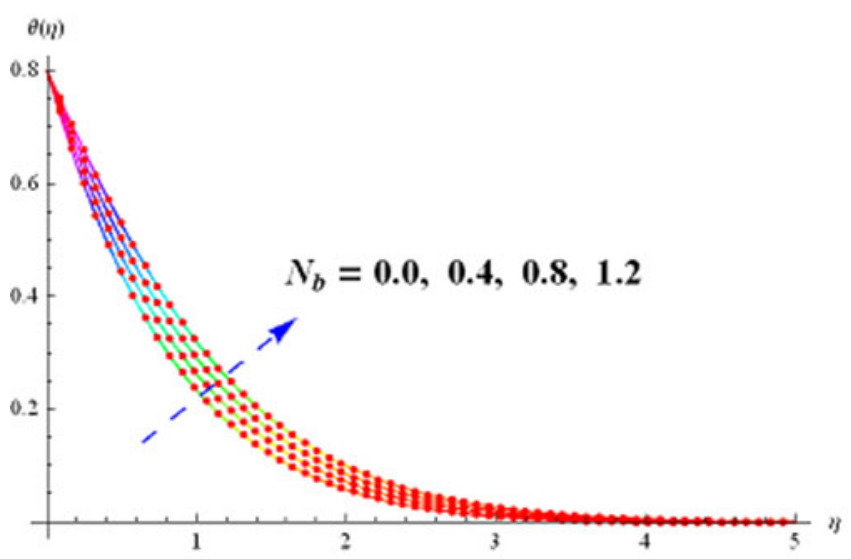

Fig. 7. $\theta$ via $N_{b}$.

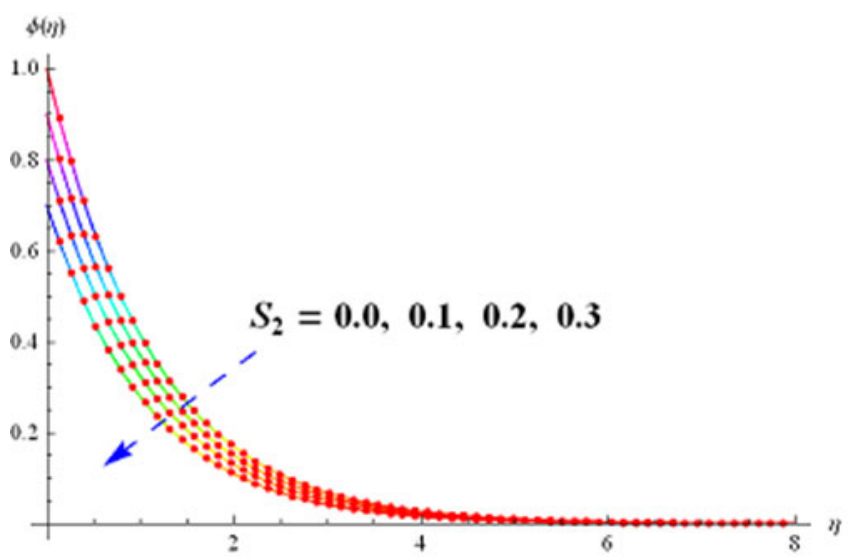

Fig. 8. $\phi$ via $S_{2}$.

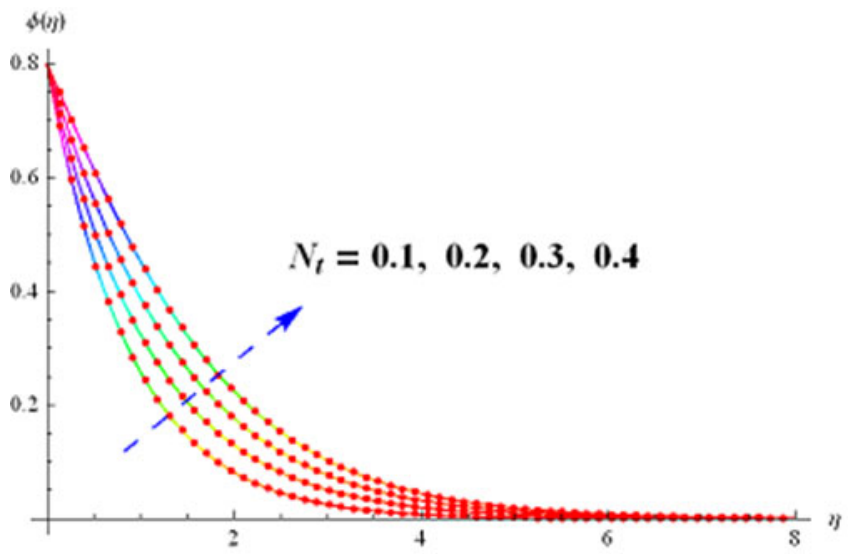

Fig. 9. $\phi$ via $N_{t}$. 


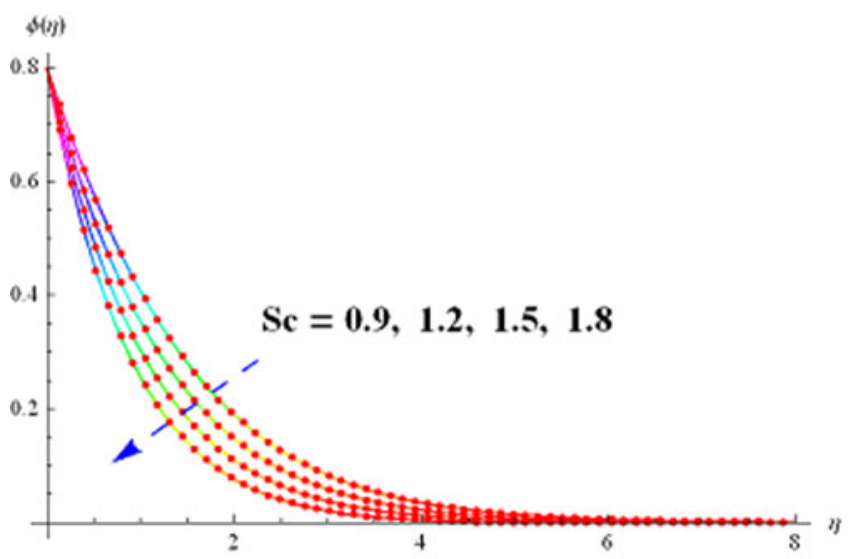

Fig. 10. $\phi$ via $S c$.

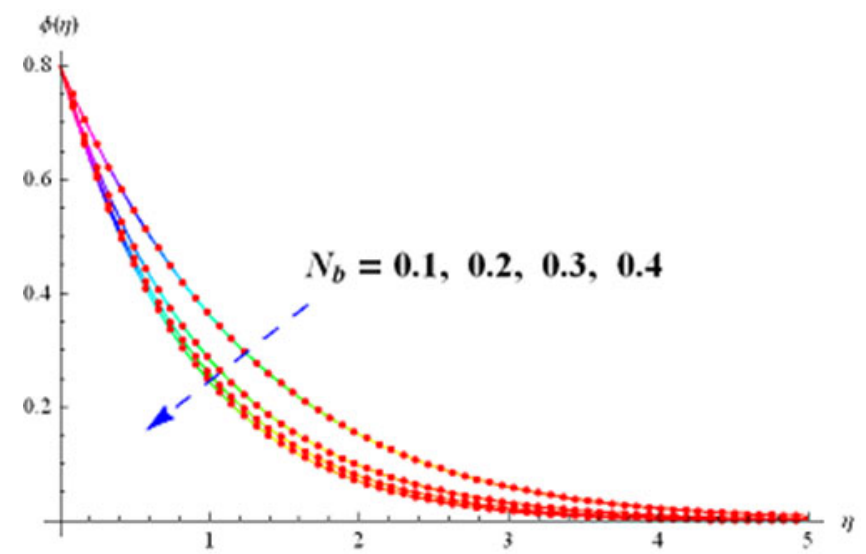

Fig. 11. $\phi$ via $N_{b}$.

\section{Conclusions}

Here the importance of heat generation and mixed convection in the doubly stratified stretching flow of an EyringPowell nanomaterial is addressed. The present investigation leads to the following key points.

- Larger $S_{1}$ and Pr lead to a reduction in $\theta$ and the corresponding layer thickness.

- Temperature $(\theta)$ increases when $S, N_{t}$ and $N_{b}$ increase.

- The Brownian motion $\left(N_{b}\right)$ and the thermophoresis $\left(N_{t}\right)$ parameters have opposite effects on $\phi$.

- The Schmidt number $(S c)$ and the solutal stratified factor $\left(S_{2}\right)$ make $\phi$ decrease.

- The heat transport rate $\left(N u_{x} \operatorname{Re}_{x}^{-\frac{1}{2}}\right)$ and Pr are directly proportional.

- Larger $N_{b}$ and $S c$ increase the mass transport rate $\left(S h_{x} \operatorname{Re}_{x}^{-\frac{1}{2}}\right)$.

- The presented analysis reduces to the viscous fluid case $\epsilon=\delta=0$.

- The absence of the Hartman number $(\mathrm{Ha})$ lead to a hydrodynamic situation.

Open Access This is an open access article distributed under the terms of the Creative Commons Attribution License (http://creativecommons.org/licenses/by/4.0), which permits unrestricted use, distribution, and reproduction in any medium, provided the original work is properly cited. 


\section{References}

1. S. Krishnamurthy, P. Bhattacharya, P.E. Phelan, R.S. Prahser, Nano Lett. 6, 419 (2006).

2. S. Ashrafmansouri, M.N. Esfahany, Int. J. Thermal Sci. 82, 84 (2014).

3. S.U.S. Choi, J.A. Eastman, Enhancing thermal conductivity of fluids with nanoparticles, in The Proceedings of the 1995 ASME International Mechanical Engineering Congress and Exposition, San Francisco, USA, FED 231/MD, 66 (ASME, 1995) pp. 99-105.

4. J. Buongiorno, ASME J. Heat Transf. 128, 240 (2006).

5. R. Ellahi, S.U. Rahman, S. Nadeem, Phys. Lett. A 378, 2973 (2014).

6. Y. Lin, L. Zheng, G. Chen, Powder Tech. 274, 324 (2015).

7. M. Sheikholeslami, S. Lohrasbi, D.D. Ganji, J. Taiwan Inst. Chem. Eng. 67, 115 (2016).

8. M. Waqas, M.I. Khan, T. Hayat, A. Alsaedi, Computer Methods Appl. Mech. Eng. 324, 640 (2017).

9. M. Khan, M. Irfan, W.A. Khan, Int. J. Mech. Sci. 130, 375 (2017).

10. S. Farooq, T. Hayat, A. Alsaedi, B. Ahmad, Int. J. Heat Mass Transfer 112, 521 (2017).

11. D. Srinivasacharya, O. Surender, Int. J. Eng. Math. 2014, 126218 (2014).

12. S.R. Mishra, P.K. Pattnaik, G.C. Dash, Alex. Eng. J. 54, 681 (2015).

13. T. Hayat, M. Waqas, M.I. Khan, A. Alsaedi, Int. J. Heat Mass Transfer 102, 1123 (2016).

14. F.M. Abbasi, S.A. Shehzad, T. Hayat, A. Alsaedi, J. Hydrodyn. Ser. B 28, 840 (2016).

15. P. Besthapu, R.U. Haq, S. Bandari, Q.M. Al-Mdallal, J. Taiwan Instit. Chem. Eng. 71, 307 (2017).

16. M. Waqas, M.I. Khan, T. Hayat, A. Alsaedi, Results Phys. (2017) https://doi.org/10.1016/j.rinp.2017.06.030.

17. C. Jiao, L. Zheng, Y. Lin, L. Ma, G. Chen, Int. J. Heat Mass Transfer 92, 700 (2016).

18. K.N. Seetharamu, V. Leela, N. Kotloni, Int. J. Heat Mass Transfer 112, 201 (2017).

19. M.I. Khan, T. Hayat, M. Waqas, M.I. Khan, A. Alsaedi, J. Mol. Liq. 233, 465 (2017).

20. M. Waqas, M.I. Khan, T. Hayat, A. Alsaedi, M.I. Khan, Eur. Phys. J. Plus 132, 280 (2017).

21. L.J. Crane, Z. Angew, Z. Angew. Math. Phys. 21, 645 (1970).

22. T. Hayat, M.S. Anwar, M. Farooq, A. Alsaedi, Int. J. Nonlinear Sci. Numer. Simul. 15, 365 (2014).

23. M. Waqas, A. Alsaedi, S.A. Shehzad, T. Hayat, S. Asghar, J. Braz. Soc. Mech. Sci. Eng. 39, 3005 (2017).

24. T. Hayat, M.I. Khan, M. Waqas, A. Alsaedi, T. Yasmeen, Chin. J. Chem. Eng. 25, 257 (2017).

25. M.I. Khan, T. Hayat, M. Waqas, A. Alsaedi, J. Mol. Liq. 230, 143 (2017).

26. I. Shufrin, M. Eisenberger, Thin-Walled Struct. 43, 189 (2005).

27. T. Fang, J. Zhang, Y. Zhong, Appl. Math. Comput. 218, 7241 (2012).

28. L. Ahmad, M. Khan, W.A. Khan, Eur. Phys. J. Plus 132, 373 (2017).

29. M.I. Khan, M.I. Khan, M. Waqas, T. Hayat, A. Alsaedi, Int. Commun. Heat Mass Transf. 86, 231 (2017).

30. T. Hayat, F. Shah, A. Alsaedi, Z. Hussain, Results Phys. (2017) https://doi.org/10.1016/j.rinp.2017.06.045.

31. S.J. Liao, Homotopic Analysis Method in Nonlinear Differential Equations (Springer, Heidelberg, 2012).

32. M. Turkyilmazoglu, Int. J. Thermal Sci. 50, 831 (2011).

33. M. Waqas, M. Farooq, M.I. Khan, A. Alsaedi, T. Hayat, T. Yasmeen, Int. J. Heat Mass Transfer 102, 766 (2016).

34. S. Qayyum, T. Hayat, A. Alsaedi, Results Phys. (2017) https://doi.org/10.1016/j.rinp.2017.07.043.

35. T. Hayat, M. Zubair, M. Waqas, A. Alsaedi, M. Ayub, Results Phys. 7, 99 (2017).

36. T. Hayat, M.I. Khan, M. Farooq, A. Alsaedi, M. Waqas, T. Yasmeen, Int. J. Heat Mass Transfer 99, 702 (2016).

37. T. Hayat, M.I. Khan, M. Farooq, T. Yasmeen, A. Alsaedi, J. Mol. Liq. 220, 49 (2016).

38. T. Hayat, A. Naseem, M. Farooq, A. Alsaedi, Eur. Phys. J. Plus 128, 158 (2013).

39. M.I. Khan, M. Waqas, T. Hayat, A. Alsaedi, J. Colloid Interface Sci. 498, 85 (2017).

40. M. Farooq, Q. Anzar, T. Hayat, M.I. Khan, A. Anjum, Results Phys. 7, 3078 (2017).

41. T. Hayat, S. Qayyum, M.I. Khan, A. Alsaedi, Int. J. Hydrogen Energy, https://doi.org/10.1016/j.ijhydene.2017.09.124 (2017).

42. N. Muhammad, S. Nadeem, Eur. Phys. J. Plus 132, 377 (2017).

43. M.I. Khan, M. Waqas, T. Hayat, M.I. Khan, A. Alsaedi, Int. J. Mech. Sci. 132, 426 (2017).

44. T. Hayat, F. Shah, A. Alsaedi, M.I. Khan, J. Theor. Comput. Chem. 16, 1750045 (2017).

45. M. Waqas, T. Hayat, S.A. Shehzad, A. Alsaedi, Physica B (2017) https://doi.org/10.1016/j.physb.2017.09.128. 